\title{
The role of infant feeding practices in the explanation for ethnic differences in infant growth: the Amsterdam Born Children and their Development study
}

\author{
Marieke L. A. de $\operatorname{Hoog}^{1,2_{*}}$, Manon van Eijsden ${ }^{2}$, Karien Stronks ${ }^{1}$, Reinoud J. B. J. Gemke ${ }^{3}$ \\ and Tanja G. M. Vrijkotte ${ }^{1}$ \\ ${ }^{1}$ Department of Public Health, Academic Medical Centre, University of Amsterdam, PO Box 22660, 1100 DD Amsterdam, \\ The Netherlands \\ ${ }^{2}$ Department of Epidemiology, Documentation and Health Promotion, Public Health Service, PO Box 2200, 1000 CE \\ Amsterdam, The Netherlands \\ ${ }^{3}$ Department of Paediatrics, EMGO Institute, Institute of Cardiovascular Research VU, VU University Medical Centre, \\ PO Box 7057, 1007 MB, Amsterdam, The Netherlands
}

(Received 5 October 2010 - Revised 17 March 2011 - Accepted 25 March 2011 - First published online 17 June 2011)

\section{Abstract}

Rapid early growth in infants may influence overweight and CVD in later life. Both rapid growth and these disease outcomes disproportionately affect some ethnic minorities. We determined ethnic differences in growth rate ( $\Delta$ standard deviation scores, $\Delta$ SDS) during the first 6 months of life and assessed the explanatory role of infant feeding. Data were derived from a multiethnic cohort for the Amsterdam Born Children and their Development study (The Netherlands). Growth data (weight and length) of 2998 term-born singleton infants with no fetal growth restriction were available for five ethnic populations: Dutch ( $n$ 1619), African descent ( $n$ 174), Turkish ( $n$ 167), Moroccan ( $n$ 232) and other non-Dutch ( $n$ 806). $\Delta$ SDS for weight, length and weight-for-length between 4 weeks and 6 months were defined using internal references. Infant feeding pattern (breast-feeding duration, introduction of formula feeding and complementary feeding) in relation to ethnic differences in growth rate was examined by multivariate linear regression. Results showed that the growth rate was higher in almost all ethnic minorities, with $\beta$ between 0.07 and 0.41 for $\Delta$ SDS weight and between 0.12 and 0.42 for $\Delta$ SDS length, compared with ethnic Dutch infants. $\Delta$ SDS weight-for-length was similar across groups, except for Moroccan infants $(\beta 0 \cdot 25, P<0 \cdot 05)$ after correction for confounders. In general, exclusive breast-feeding for 4 months was associated with slower growth for all three growth measures. Feeding factors explained, to a small degree, the higher weight and length gain in African descent infants, but not the higher $\Delta$ SDS weight-for-length in the Moroccan population. More research is needed to elucidate the underlying mechanisms of the high infant growth rate in Turkish and Moroccan infants.

Key words: Infants: Excessive weight gain: Ethnicity: Infant feeding: Amsterdam Born Children and their Development study

Childhood obesity is a serious medical condition that affects children and adolescents. It is an epidemic health problem worldwide. In the USA, $17 \%$ of children and adolescents (2-19 years) are overweight or obese, and this number is still rising ${ }^{(1)}$. It is particularly troubling because the extra weight can lead to health problems, such as type 2 diabetes, high blood pressure and high cholesterol, that were once confined to adults ${ }^{(2-6)}$.

Children from some ethnic minorities are more affected by overweight than others. Studies in Europe ${ }^{(7-9)}$ and in the $\mathrm{USA}^{(10-12)}$ have shown that ethnicity is a consistent correlate of childhood obesity; in the Netherlands, especially children from Turkish and Moroccan origin have the largest prevalence $(25-30 \%)$ of overweight ${ }^{(7,13)}$.
There is compelling evidence that many of the risks leading to obesity and its related disorders in adulthood originate in the earliest stages of life. Adverse environmental conditions in utero and during infancy (e.g. growth acceleration) can lead to negative health effects during the subsequent lifetime of the exposed individual (known as the developmental origins of health and disease hypothesis) ${ }^{(14-16)}$. Recent results of the Amsterdam Born Children and their Development (ABCD) study have shown that ethnic differences in overweight children already exist at the age of 2 years, with higher BMI for the Turkish and Moroccan children compared with the ethnic Dutch children ${ }^{(17)}$. Results of this study, as well as others ${ }^{(18)}$, suggested that weight gain in the first few months of life, which in turn

Abbreviations: ABCD, Amsterdam Born Children and their Development; SDS, standard deviation scores.

*Corresponding author: M. L. A. de Hoog, fax +31 20697 2316, email m.l.dehoog@amc.uva.nl 
may be affected by feeding practices, plays an important role in later life.

Both breast-feeding and the early introduction of complementary foods $(<4$ months $)$ are infant feeding practices that can have an important effect on growth ${ }^{(19-22)}$. Nutritional studies into the growth pattern of breast- and formula-fed children describe that a long duration of part or exclusive breastfeeding can modulate growth in weight in infancy ${ }^{(21,23)}$, and may reduce the risk of overweight in childhood ${ }^{(21)}$. Although previous studies showed inconsistent associations ${ }^{(24,25)}$, late introduction of complementary food may have a beneficial effect on body fat percentage, blood pressure and adult weight ${ }^{(26,27)}$. There is evidence that feeding patterns differ among ethnic groups. Breast-feeding is more common in Turkish and Moroccan mothers compared with ethnic Dutch mothers; however, Turkish and Moroccan mothers start earlier with additional bottle feeding ${ }^{(28,29)}$. Furthermore, African American mothers in general have a shorter duration of breast-feeding and introduce solid food much earlier ${ }^{(30-32)}$. Nevertheless, it is unknown to what extent these feeding factors influence growth across ethnic minorities and whether they explain possible ethnic differences in growth.

Most studies use weight gain (absolute weight gain or weight-for-age) to define growth in infancy. The combination of weight and length measures reflects adiposity better than weight alone ${ }^{(33)}$. Relative weights are affected not only by adiposity but also by other factors such as skeletal width and muscular development. In addition, there are indications that infant feeding is not only related to weight gain but also to growth in length and weight-for-length ${ }^{(34)}$.

The present study focuses on ethnic differences in growth in weight, length and weight-for-length during the first 6 months of life and the explanatory role of infant feeding. For this purpose, data from the ABCD study were used. Based on the previously mentioned literature, we hypothesise that the duration of breast-feeding and the introduction of formula and complementary feeding during infancy have an influence on infant growth in all ethnic groups, and that differences in infant feeding practices among ethnic groups contribute to faster growth rate in infants from non-Dutch origin. We assessed growth rate as gain in standardised weight, length and weight-for-length between 4 weeks and 6 months.

\section{Methods}

\section{Subjects}

The design and rationale of the ABCD study have been described previously ${ }^{(35)}$. In brief, between January 2003 and March 2004, 12373 pregnant women were approached to participate in the study at their first antenatal visit to an obstetric caregiver (median 13 weeks; interquartile range 3 weeks). Of this group, 8266 (response rate 67\%) women filled out an extensive pregnancy questionnaire about socio-demographic data, obstetric history, lifestyle, dietary habits and psychosocial conditions (phase 1). Of these respondents, 7863 women gave birth to a viable singleton infant for whom information on birth weight and pregnancy duration was available (twins were excluded due to other development characteristics). Of these women, 6575 gave permission for collecting growth data and infant feeding information from the Youth Health Care files, and 5131 of them filled out a questionnaire about their baby (health, feeding and behaviour) (phase 2). Currently, data on growth and infant feeding patterns (breast-feeding, introduction of formula feeding and complementary feeding) from 5273 of these children have been digitised, and data collection is still ongoing. Phase 3 of the study started in the summer of 2008. Around 2 weeks after their ABCD-child's fifth birthday, mothers who initially gave permission for follow-up received a questionnaire about the child's health, development and behaviour. This questionnaire contained questions about the child's feeding pattern in infancy. Data collection is ongoing.

The study population for the present study includes 3702 mother-child pairs with a known feeding pattern (duration of breast-feeding and introduction of formula feeding and complementary foods) in the first 6 months, plus known height and weight data of the child measured at the age of 4 weeks (range 1-10 weeks; mean 4.8 weeks) and 6 months (26 weeks; range 23-29 weeks; mean 27.7 weeks), which are routine follow-up moments at these ages. After exclusion of children born at $<37$ weeks gestation ( $n$ 194), the $10 \%$ of children born small-for-gestational age $(<\mathrm{P} 10 ; n 461)$ and cases with other missing values ( $n 78)$, the final sample for the analysis was 2998 children.

The present study was conducted according to the guidelines laid down in the Declaration of Helsinki, and all procedures involving human subjects were approved by the review boards of all Amsterdam hospitals and the Registration Committee of Amsterdam. Written informed consent was obtained from all subjects.

\section{Measurements}

Ethnicity was based on the country of birth of the pregnant woman and her mother to include both first (born outside the Netherlands) and second (born in the Netherlands, but with a mother born in another country) generation women $^{(36)}$. After exploring the data by ethnicity, we found comparable growth and feeding patterns for the people from African descent (Surinam-Creole, Antillean and Ghanaian). Therefore, for the present study, we combined these children into one group 'African descent'. The study distinguishes between five ethnic groups: Dutch native ( $n$ 1619), African descent ( $n$ 174), Turkish ( $n$ 167), Moroccan ( $n$ 232) and other (Western and non-Western, $n$ 806).

Data on growth and infant feeding practices (breast-feeding, introduction of formula feeding and complementary feeding) were obtained from the Youth Health Care registration of Public Health Service in Amsterdam. Following a standard procedure, trained nurses measured weight and height on average twelve times between the ages of birth and 4 years (first measurement of weight took place at birth and length after 1 month of age). The primary outcome variable for the present study was $\Delta$ standard deviation scores ( $\Delta$ SDS) for 
weight, length and weight-for-length. This was calculated as the SDS at 6 months minus the SDS at 4 weeks. SDS was defined by new internal sex-specific reference charts, based on data from the ABCD study ${ }^{(17)}$. The LMS (lambda-musigma) method was used to generate the reference curves. The curves were fitted using the Box-Cox power formula.

Besides the information about infant feeding from the Youth Health Care centre, we used the information on the infant questionnaire and the retrospective information in the 5-year questionnaire, which is described earlier, to complete our data about infant feeding. The intra-class correlation coefficient, an index of the reliability between the sources, ranged between 0.76 and $0.79(P<0.05)$, indicating that infant feeding can reliably be reported retrospectively after 5 years. We used the following infant feeding variables: duration of breast-feeding (none, < 1 month, 1-3 months, 4-6 months and >6 months); age at the introduction of formula feeding (none, $<1$ month, 1-3 months, 4-6 months and >6 months); age at the introduction of complementary food $(<4$ months, 4 months, 5 months and $>5$ months).

Selected confounders were based a priori on earlier literature showing the influence on early growth ${ }^{(28,37)}$. The prenatal confounders were maternal age (years), education (years of education after primary school: $\leq 5,6-10$ and $>10$ years) smoking habits (no, $1-5$ or $>5$ cigarettes) during pregnancy, diabetes (no, pre-existent and gestational), hypertension (no, pre-existent and gestational) and pre-pregnancy BMI $\left(\mathrm{kg} / \mathrm{m}^{2}\right)$ based on self-reported height and weight $(<18.5,18.5-20$, $20-25,25-30$ and $>30)$, parity $(0,1$ and $\geq 2)$ and maternal and paternal height $(\mathrm{cm})$. Maternal weight and height and paternal height were imputed to complete missing data. The birth outcome covariates were birth weight (standardised for parity, gestational age and sex) and gestational age (weeks).

\section{Data analysis}

Demographic differences as well as infant feeding patterns between ethnic groups were examined with $\chi^{2}$ tests (categorical data) or ANOVA (continuous data). Linear regression was used to analyse the association between infant feeding and the three early growth rate measures: $\Delta$ SDS weight, $\Delta$ SDS length and $\Delta$ SDS weight-for-length. First, the three infant feeding factors (duration of breast-feeding, and age at introduction of bottle feeding and complementary feeding) were analysed separately, and second, the three infant feeding factors were combined in one variable to construct a combined infant feeding pattern according to Ong et al. ${ }^{(34)}$. The following categories were distinguished: exclusive breast-feeding for at least 4 months; breast-feeding combined with bottle feeding and/or complementary feeding before the age of 4 months; bottle feeding with or without complementary food at 4 months.

Ethnic differences in $\Delta$ SDS weight, $\Delta$ SDS length and $\Delta$ SDS weight-for-length and the role of infant feeding were assessed with multivariable linear regression. Analyses followed a rational hierarchical format. First, univariate analyses (only adjustment for maternal age was made) were performed. Subsequently, three models (forced entry) were built to assess the role of the potential explanatory factors in the association between growth in the first 6 months of life and ethnicity. The first multivariable model included, in addition to ethnicity and maternal age, the covariates (smoking habits, diabetes, hypertension, parity and parental height, living with partner, standardised birth weight and gestational age). The second model also included the feeding factors (duration of breast-feeding, and age at introduction of formula feeding and complementary food). Because both pre-pregnancy BMI and maternal education have an association with growth and feeding, the final and third model also included these factors to complete the analyses. Results are shown as $\beta$ and 95\% CI using the ethnic Dutch group as the reference. Feeding factors were considered as explaining factors with a change in $\beta$ of $>10 \%$ between models 1 and 2 . Statistical analyses were conducted using SPSS version 17.0 (for Windows). A $P$ value $<0.05$ was regarded as significant.

\section{Results}

The baseline characteristics according to the ethnic groups are shown in Table 1. Dutch women were generally older, higher educated, had lower BMI, had more first-born children and were in general taller than women of non-Dutch origin $(P<0 \cdot 001)$. Turkish women reported smoking more often than other women, and African women were more often single $(P<0 \cdot 001)$. The infants from African origin had on average the lowest birth weight and shortest gestational age $(P<0 \cdot 001)$. The weight and length gain per month was higher in all non-Dutch infants compared with the Dutch infants $(P<0 \cdot 001)$.

The final group studied with data on growth and infant feeding (response group $n$ 2998) was compared with the nonresponse group who completed the pregnancy questionnaire (n 3790; infants born pre-term and small-for-gestational age excluded). The groups were comparable with respect to almost all measured demographic and lifestyle variables $(P>0.05)$, with the exception of the Dutch mothers in the response group being older and taller and suffering more from gestational hypertension and less from pre-existent hypertension. The Turkish mothers in the response group were more often smokers, and the 'other' group was generally older and had more often gestational hypertension (all, $P<0 \cdot 04$ ).

\section{Ethnic differences in feeding habits}

The initiation rate for breast-feeding was highest in the Turkish women $(97.6 \%)$ followed by the Moroccan women (92.2\%) and was the lowest in the Dutch women (83.6\%). The percentage of infants who received breast-feeding for at least 6 months was highest in the Turkish group (46.3\%) and lowest in the African descent group (23.6\%). Of the African descent infants, $76.4 \%$ received formula feeding before the 4th month of age, followed by the Moroccan infants (67.3\%). The African descent infants received in general a short period of breast-feeding, and the Moroccan infants received a prolonged duration of mixed feeding. Early introduction of complementary food $(<4$ th month) was mainly 
Table 1. Characteristics of the study sample according to ethnic group

(Mean values and standard deviations)

\begin{tabular}{|c|c|c|c|c|c|c|c|c|c|c|c|}
\hline & \multicolumn{2}{|c|}{ Dutch ( $n$ 1619) } & \multicolumn{2}{|c|}{$\begin{array}{l}\text { African descent } \\
\qquad(n 174)\end{array}$} & \multicolumn{2}{|c|}{ Turkish (n 167) } & \multicolumn{2}{|c|}{$\begin{array}{l}\text { Moroccan } \\
(n 232)\end{array}$} & \multicolumn{2}{|c|}{ Others ( $n 806)$} & \multirow[b]{2}{*}{$P$} \\
\hline & Mean & SD & Mean & SD & Mean & SD & Mean & SD & Mean & SD & \\
\hline \multicolumn{12}{|l|}{ General factors } \\
\hline \multicolumn{12}{|l|}{ Related to the mother } \\
\hline Age (years) & $32 \cdot 4$ & $4 \cdot 1$ & $29 \cdot 5$ & $6 \cdot 4$ & $25 \cdot 8$ & $5 \cdot 0$ & $27 \cdot 9$ & $5 \cdot 4$ & 31.5 & 4.9 & $\star \star \star *$ \\
\hline \multicolumn{12}{|l|}{ Parity (\%) } \\
\hline 0 & \multicolumn{2}{|c|}{$59 \cdot 2$} & \multicolumn{2}{|c|}{$44 \cdot 8$} & \multicolumn{2}{|c|}{$46 \cdot 1$} & \multicolumn{2}{|c|}{43.5} & \multicolumn{2}{|c|}{$54 \cdot 2$} & $* \star *$ \\
\hline$\geq 1$ & \multicolumn{2}{|c|}{$40 \cdot 8$} & \multicolumn{2}{|c|}{$55 \cdot 2$} & & & & & & & \\
\hline Maternal height (cm) & 172 & $6 \cdot 1$ & 167 & $6 \cdot 0$ & 162 & $5 \cdot 6$ & 164 & $6 \cdot 5$ & 166 & $7 \cdot 1$ & $\star \star \star *$ \\
\hline Paternal height $(\mathrm{cm})$ & 184 & $7 \cdot 2$ & 177 & $8 \cdot 0$ & 176 & $7 \cdot 1$ & 176 & $7 \cdot 0$ & 181 & $8 \cdot 4$ & 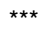 \\
\hline BMI of mother $\left(\mathrm{kg} / \mathrm{m}^{2}\right)$ & $22 \cdot 7$ & $3 \cdot 4$ & 24.9 & $5 \cdot 6$ & $24 \cdot 3$ & $4 \cdot 2$ & 25.5 & $4 \cdot 6$ & $22 \cdot 7$ & $3 \cdot 8$ & $\star \star \star *$ \\
\hline Hypertension (\%) & & & & & & & & & & & \\
\hline Gestational age & & & & & & & & & & & 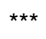 \\
\hline Pre-existent & & & & & & & & & & & \\
\hline Diabetes (\%) & & & & & & & & & & & \\
\hline Gestational & & & & & & & & & & & *** \\
\hline Pre-existent & & & & & & & & & & & \\
\hline Smoking during pregnancy (\%) & & & & & & & & & & & \\
\hline $1-5$ cigarettes/d & & & & & & & & & & & *** \\
\hline$\geq 6$ cigarettes $/ d$ & & & & & & & & & & & \\
\hline Maternal education (\%) & & & & & & & & & & & \\
\hline $1-5$ years & & & & & & & & & & & $\star \star \star *$ \\
\hline $6-10$ years & & & & & & & & & & & \\
\hline$\geq 10$ years & & & & & & & & & & & \\
\hline Living together with partner (\% yes) & & & & & & & & & & & *** \\
\hline Related to the child & & & & & & & & & & & \\
\hline Birth weight (kg) & 3.65 & 0.43 & 3.51 & 0.40 & 3.53 & 0.39 & 3.60 & 0.39 & 3.56 & 0.41 & $\star \star \star *$ \\
\hline $\operatorname{Sex}(\%)$ & & & & & & & & & & & \\
\hline Boy & & & & & & & & & & & \\
\hline Girl & & & & & & & & & & & \\
\hline Gestational age (weeks) & $40 \cdot 2$ & $1 \cdot 2$ & $39 \cdot 7$ & $1 \cdot 1$ & 39.9 & $1 \cdot 2$ & $40 \cdot 1$ & $1 \cdot 3$ & $40 \cdot 0$ & $1 \cdot 2$ & *** \\
\hline LGA (\%) & & & & & & & & & & & \\
\hline Weight of child at 6 months $(\mathrm{kg})$ & $7 \cdot 8$ & 0.9 & $8 \cdot 0$ & $1 \cdot 0$ & $8 \cdot 3$ & 0.9 & $8 \cdot 0$ & 0.9 & $7 \cdot 7$ & 0.8 & *** \\
\hline Length of child at 6 months $(\mathrm{cm})$ & 68 & 2.4 & 68 & 2.4 & 68 & 2.4 & 67 & 2.4 & 67 & $2 \cdot 3$ & $\star \star \star *$ \\
\hline Weight gain per month $(\mathrm{g})$ & 703 & 128 & 760 & 155 & 802 & 152 & 749 & 147 & 707 & 129 & *** \\
\hline Length gain per month (cm) & 2.5 & 0.4 & $2 \cdot 7$ & 0.4 & $2 \cdot 7$ & 0.3 & $2 \cdot 6$ & 0.4 & $2 \cdot 6$ & 0.4 & *** \\
\hline Feeding factors & & & & & & & & & & & \\
\hline Duration of breast-feeding (\%) & & & & & & & & & & & \\
\hline None & & & & & & & & & & & *** \\
\hline$<1$ month & & & & & & & & & & & \\
\hline $1-3$ months & & & & & & & & & & & \\
\hline $3-6$ months & & & & & & & & & & & \\
\hline$\geq 6$ months & & & & & & & & & & & \\
\hline Start formula feeding (\%) & & & & & & & & & & & \\
\hline Birth & & & & & & & & & & & *** \\
\hline$<1$ month & & & & & & & & & & & \\
\hline $1-3$ months & & & & & & & & & & & \\
\hline $3-6$ months & & & & & & & & & & & \\
\hline$\geq 6$ months & & & & & & & & & & & \\
\hline Start complementary food (\%) & & & & & & & & & & & \\
\hline$<4$ months & & & & & & & & & & & *** \\
\hline 4 months & & & & & & & & & & & \\
\hline 5 months & & & & & & & & & & & \\
\hline$>5$ months & & & & & & & & & & & \\
\hline
\end{tabular}

LGA, large-for-gestational age.

Mean values were significantly different between ethnic origins: ${ }^{\star \star \star} P<0.001$.

present in the African descent infants (10.3\%). The lowest percentage was found in the Turkish infants $(1 \cdot 2 \%)$.

\section{Infant feeding practices and growth rate}

Table 2 shows the infant feeding factors and the association with the three measures of early growth rate. It clearly shows that a shorter duration of breast-feeding is highly associated with higher weight and length gain $(P<0 \cdot 01)$. The association with weight-for-length gain is also positive and significant, although less pronounced and became less significant after correction for confounders. Figs. 1-3 show the association between the combined infant feeding pattern at the age of 4 months and infant growth rate (weight, length and weight-for-length) for each ethnic group separately. In most groups, exclusive breast-feeding for at least 
4 months was significantly associated with the slowest growth in weight, length and weight-for-length. This pattern was less clear in the Turkish group; however, no infant feeding pattern $\times$ ethnicity interaction was detected for any of the growth rate measures $(P>0 \cdot 10)$.

\section{Ethnic differences in $\Delta$ standard deviation scores weight}

$\Delta$ SDS weight was higher in the African descent $(0 \cdot 39 ; 95 \% \mathrm{CI}$ $0.25,0.53)$, Turkish $(0.41 ; 95 \%$ CI $0.27,0.56)$ and Moroccan $(0 \cdot 26 ; 95 \%$ CI $0 \cdot 14,0 \cdot 39)$ infants compared with the ethnic Dutch infants (Table 3).

After adjusting for potential confounders (model 1), the multivariable analyses showed a minor change in $\Delta$ SDS weight in all groups. The associations remained significant for the African descent, Turkish and Moroccan infants. After adding the feeding factors (model 2), $\Delta$ SDS weight decreased slightly in the African descent infants but remained significant. $\Delta$ SDS weight in all other groups increased and was significantly higher compared with the ethnic Dutch group. In the final model, model 3, $\Delta$ SDS weight decreased in all groups after adjustment for maternal pre-pregnancy BMI and education level (mostly due to the addition of education level) but remained significantly higher (African descent: 0.23; $95 \%$ CI 0.09, 0.36; Turkish: 0.43; 95\% CI 0.29, 0.58 and Moroccan: $0 \cdot 29 ; 95 \%$ CI $0 \cdot 16,0 \cdot 41)$.

\section{Ethnic differences in $\Delta$ standard deviation scores length}

All ethnic minority infants had increased $\Delta$ SDS length compared with the ethnic Dutch infants (Table 3). We found the highest $\Delta$ SDS length in the Turkish infants (0.42; CI 0.27, 0.57).

After adding the potential confounders, $\Delta$ SDS length in the African descent infants showed a slight decrease (0.40; $95 \% \mathrm{CI}$ $0 \cdot 26,0.54 v \cdot 0 \cdot 34 ; 95 \%$ CI $0 \cdot 20,0 \cdot 49)$. $\Delta$ SDS length in all other groups hardly attenuated or even increased (model 1; Table 3 ). The same pattern was observed when adding the feeding factors into model 2. The final model (model 3) showed a slight decrease in $\Delta$ SDS length in all ethnic groups (mostly due to the addition of education level); however, the association between growth in length and ethnicity remained.

\section{Ethnic differences in $\Delta$ standard deviation scores weight-for-length}

There were no ethnic differences in $\Delta$ SDS weight-for-length in the crude analyses (Table 3). However, after adjustment for confounders, Moroccan infants showed higher growth rate in weight-for-length compared with Dutch infants $(0 \cdot 25 ; 95 \%$ CI $0 \cdot 08,0 \cdot 41)$, which was not explained by feeding factors.

\section{Discussion}

The present study showed ethnic differences in growth rate regarding faster gain in weight and length for Turkish, Moroccan and African descent infants compared with the Dutch, and in addition also in weight-for-length for the Moroccan infants. Their accelerated growth in the first 6 months of life, 


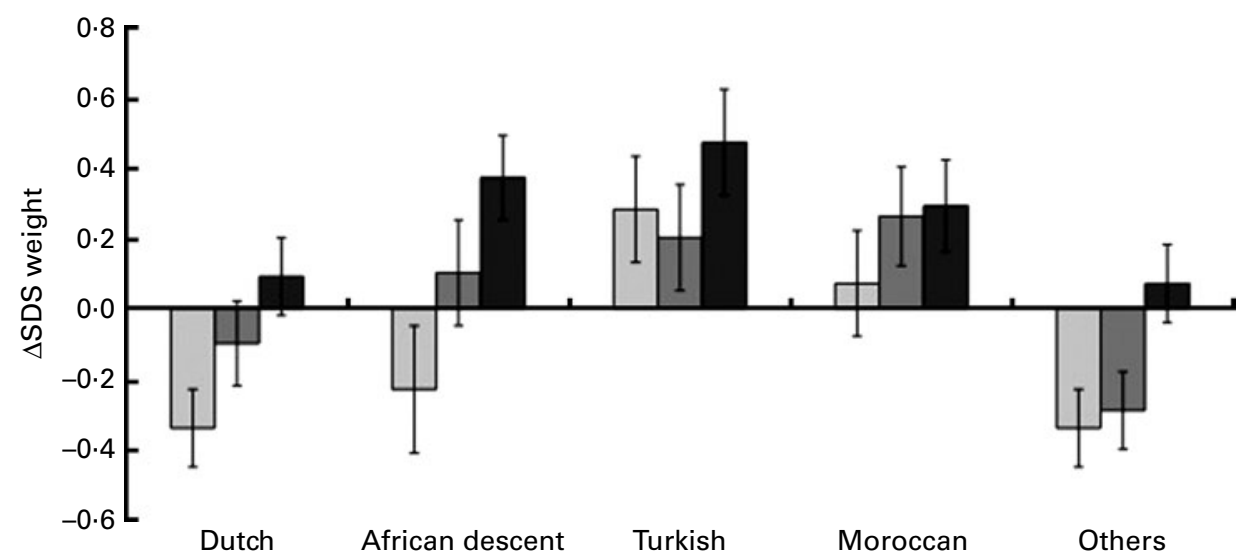

in contrast to our expectations, was not explained by feeding pattern during infancy. Only the weight increase in the African descent infants was partly explained by the shorter duration of breast-feeding and the early introduction of formula feeding. The unbalanced growth in the Moroccan infants (more growth in weight compared with that in length) may put them at higher risk for overweight and obesity in adult life. In general, we found that breast-feeding, irrespective of ethnicity, results in slower gain in weight and length during the first 6 months of life in all ethnic groups; however, in the Turkish infants, this pattern was less clear.

There is increasing evidence that accelerated early growth has a positive association with overweight and obesity $^{(18,26,38,39)}$. For example, infants with postnatal catch-up in weight (SDS >0.67) have a higher fat mass percentage at 6 months $^{(40)}$. According to Botton et al. ${ }^{(41)}$, two periods in early life are associated with body composition during adolescence (8-17 years): the first 6 months of life and the period after the age of 2 years. We found ethnic differences in growth in the first 6 months with the highest weight and length gain in the Turkish infants followed by children from African descent and the Moroccan infants. These findings imply that these infants may have a higher risk for becoming overweight compared with ethnic Dutch infants.

We found associations between growth in weight and length and the individual feeding factors. Long duration of breast-feeding ( $>4$ months), and late introduction of formula feeding ( $>4$ months) and complementary food ( $>5$ months) were found to be protective against growth acceleration in weight and length. When exploring a more combined feeding pattern, the present results (Figs. 1-3) confirm the large and increasing body of evidence indicating a protective effect of exclusive breast-feeding above the mixed breast/formula feeding or formula feeding alone on growth during the first months of life $\mathrm{e}^{(22,23,26,42)}$. Comparable with the present study, Ong et al. ${ }^{(34)}$ found that dietary energy intake at 4 months was associated with larger body weight SDS among formula- or mixed-fed children, but not with breast-fed children. Another study concerning BMI and early feeding by Chivers et al. ${ }^{(42)}$ also stresses the importance of exclusive breast-feeding for at least 4 months.

Comparable with the present study, Bulk-Bunschoten et $a l^{(28)}$ found that mothers from Turkish and Moroccan origin breast-fed more and with a longer duration compared with Dutch mothers. Yet, they introduced bottle feeding

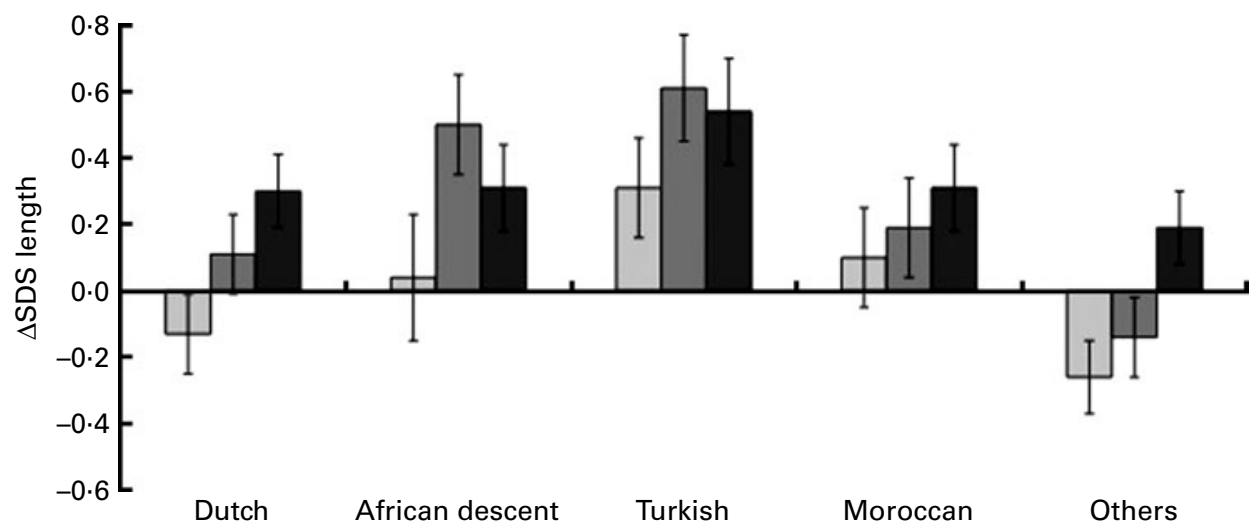

Fig. 2. Effect of infant feeding pattern in the 4th month on $\Delta$ standard deviation scores $(\Delta S D S)$ for length. $\Delta$ SDS length adjusted for parental height, smoking during pregnancy, hypertension, diabetes, parity, living with partner, gestational age, standardised birth weight and ethnicity $\times$ feeding pattern. $\square$, Exclusive breast-feeding; $\square$, breast-feeding with formula and/or complementary feeding; $\square$, formula feeding with or without complementary feeding. 


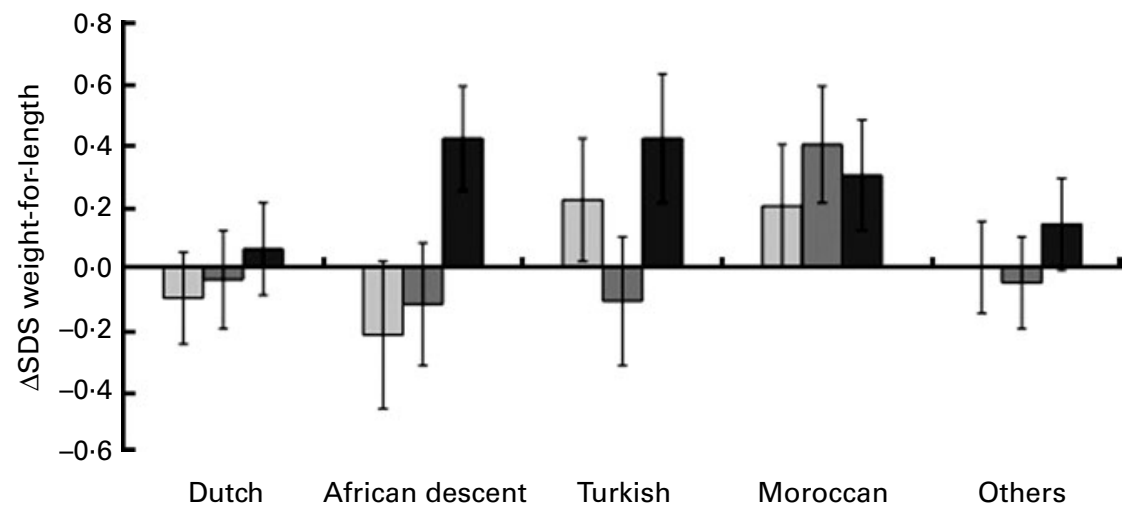

Fig. 3. Effect of infant feeding pattern in the 4th month on $\Delta$ standard deviation scores $(\Delta S D S)$ for weight-for-length. $\Delta$ SDS weight-for-length adjusted for parental height, smoking during pregnancy, hypertension, diabetes, parity, living with partner, gestational age, standardised birth weight and ethnicity $\times$ feeding pattern. $\square$, Exclusive breast-feeding; $\square$, breast-feeding with formula and/or complementary feeding; $\square$, formula feeding with or without complementary feeding.

earlier, which resulted in a longer period of mixed feeding as opposed to exclusive breast-feeding ${ }^{(28)}$, which was also observed in the present study mainly in the Moroccan and the Turkish infants. This may result in more growth acceleration in weight and length compared with the children who were exclusively breast-fed. This phenomenon was not present in the African descent women. These infants were breast-fed for a shorter period and had an earlier introduction of formula and complementary feeding. The Dutch health care system recommends introducing complementary food between the ages of 4 and 6 months. The present results, and those from other studies ${ }^{(22,37,43)}$, show that mothers from African descent are less likely to follow these guidelines and introduce complementary food earlier. This infant feeding pattern, e.g. early bottle feeding and complementary feeding, could result in the fastest gain in weight and length at this age.
The differences in feeding pattern that we found between the ethnicities (Dutch, Turkish, Moroccan and African descent) are remarkable, especially with regard to initiation and duration of breast-feeding and the introduction of formula feeding. This could be due to several factors. First, Turkish and Moroccan mothers may be influenced by the Koran, which commands a breast-feeding duration of 2 years. Second, previous results of the ABCD study showed that the attitude of the father and grandmother is an important determinant of breast-feeding behaviour in Turkish women in particular $^{(44)}$. These results from the ABCD study show that women of Turkish origin were more stimulated by their relatives to breast-feed than the Dutch and Surinamese (African) families. Furthermore, environmental factors such as a workplace setting may interact with a mother's ambivalence about breast-feeding ${ }^{(30)}$. A study in the USA reported that

Table 3. Multivariate analyses for $\Delta$ standard deviation scores ( $\Delta$ SDS) for weight, length and weight-for-length as a function of ethnicity

( $\beta$ Coefficients and $95 \%$ confidence intervals)

\begin{tabular}{|c|c|c|c|c|c|c|c|c|}
\hline & \multicolumn{2}{|c|}{ Crude* $^{*}$} & \multicolumn{2}{|c|}{ Model 1† } & \multicolumn{2}{|c|}{ Model 2‡ } & \multicolumn{2}{|c|}{ Model 3§ } \\
\hline & $\beta$ & $95 \% \mathrm{Cl}$ & $\beta$ & $95 \% \mathrm{Cl}$ & $\beta$ & $95 \% \mathrm{Cl}$ & $\beta$ & $95 \% \mathrm{Cl}$ \\
\hline \multicolumn{9}{|l|}{$\Delta$ SDS weight } \\
\hline Dutch & $0 \cdot 0$ & & 0.0 & & $0 \cdot 0$ & & 0.0 & \\
\hline African descent & 0.39 & $0.25,0.53$ & 0.31 & $0.17,0.45$ & 0.27 & $0.13,0.40$ & 0.23 & $0.09,0.36$ \\
\hline Turkish & 0.41 & $0.27,0.56$ & 0.43 & $0.29,0.58$ & 0.48 & $0.34,0.62$ & 0.43 & $0.29,0.58$ \\
\hline Moroccan & 0.26 & $0.14,0.39$ & 0.37 & $0.24,0.49$ & 0.35 & $0.23,0.47$ & 0.29 & $0.16,0.41$ \\
\hline Others & 0.07 & $-0.00,0.14$ & 0.06 & $-0.02,0.13$ & 0.06 & $-0.01,0.13$ & 0.05 & $-0.02,0.13$ \\
\hline \multicolumn{9}{|l|}{$\Delta$ SDS length } \\
\hline Dutch & 0.0 & & 0.0 & & $0 \cdot 0$ & & $0 \cdot 0$ & \\
\hline African descent & 0.40 & $0.26,0.54$ & 0.34 & $0.20,0.49$ & 0.30 & $0.16,0.44$ & 0.26 & $0.12,0.41$ \\
\hline Turkish & 0.42 & $0.27,0.57$ & 0.49 & $0.34,0.64$ & 0.55 & $0.41,0.70$ & 0.50 & $0.34,0.65$ \\
\hline Moroccan & 0.14 & $0.02,0.26$ & 0.25 & $0.12,0.38$ & 0.24 & $0.11,0.37$ & 0.18 & $0.05,0.31$ \\
\hline Others & 0.12 & $0.05,0.20$ & 0.15 & $0.07,0.23$ & $0 \cdot 16$ & $0.08,0.23$ & $0 \cdot 14$ & $0.06,0.22$ \\
\hline \multicolumn{9}{|c|}{$\Delta$ SDS weight-for-length } \\
\hline Dutch & 0.0 & & 0.0 & & 0.0 & & 0.0 & \\
\hline African descent & 0.02 & $-0.16,0.19$ & 0.08 & $-0.10,0.27$ & 0.06 & $-0.13,0.24$ & 0.05 & $-0.14,0.24$ \\
\hline Turkish & 0.04 & $-0.14,0.22$ & 0.11 & $-0.09,0.30$ & 0.12 & $0.08,0.31$ & $0 \cdot 12$ & $-0.09,0.32$ \\
\hline Moroccan & 0.13 & $-0.03,0.28$ & 0.25 & $0.08,0.41$ & 0.23 & $0.06,0.39$ & 0.22 & $0.04,0.39$ \\
\hline Others & -0.08 & $-0.17,0.01$ & -0.07 & $-0.16,0.03$ & -0.07 & $-0.16,0.03$ & -0.06 & $-0.16,0.05$ \\
\hline
\end{tabular}

* Standardised for maternal age.

† Adjusted for confounders (parental height, hypertension, diabetes, smoking during pregnancy, parity, living with partner, gestational age and standardised birth weight).

¥ Model 1 plus feeding factors (duration of breast-feeding, start formula feeding and introduction of complementary food).

$\S$ Model 2 plus maternal BMI and education level. 
African American mothers were more likely to report that they had stopped breast-feeding in order to return to work, because their work conditions may be less hospitable to breast-feeding ${ }^{(45)}$.

The ethnic differences in growth are not explained by feeding practices in our cohort and which applies especially to the Moroccan and Turkish infants. The question why these children grow faster in the first 6 months of life has not been answered. Other factors for which we did not account (e.g. quantity of the food or the type of formula feeding) may play a role in explaining ethnic differences in growth with infant feeding. To give additional formula feeding in the presence of complete breast-feeding is more common in Turkish and Moroccan women ${ }^{(28)}$. However, this is not likely to be the explanation for the present results, because the Turkish and Moroccan infants who received breast-feeding as well as bottle feeding at the age of 4 months (Figs. 1-3) did not show the fastest growth rate. Another explanation could be a different composition of the breast milk resulting from different eating habits.

Alternatively, many studies have shown that intra-uterine growth retardation and being born pre-term are highly associated with accelerated postnatal growth ${ }^{(46,47)}$. Results from our cohort have already shown that women from African decent give birth to children with the lowest birth weight, and that they have the shortest gestational age. We deliberately selected term-born children and excluded those with a birth weight below the 10th percentile to minimise these influences. Despite these selections, the African decent infants have the lowest birth weight and their high $\Delta$ SDS is the result of a low SDS at 4 weeks.

Otherwise, there may be a genetic component providing the increased growth in the different ethnic groups ${ }^{(48)}$. Striking is that the tallest Dutch population has the slowest growth from birth to the age of 6 months in both weight and length. Although earlier studies describe that child growth is mainly influenced by socio-economic status and not by race or ethnicity $^{(49,50)}$, it is possible that there are developmental differences. For example, the fifth Dutch growth study found that children, both boys and girls, from Turkish origin have more length gain in the first year of life (girls: 75.6 (SD $2.5) \mathrm{cm}$ and boys: $77.3(\mathrm{SD} 2.7) \mathrm{cm})$, compared with the ethnic Dutch children (girls: 75.0 (SD $2 \cdot 8$ ) $\mathrm{cm}$ and boys: 76.7 $(\mathrm{SD} 2 \cdot 7) \mathrm{cm}$ ). During the second year, Turkish boys are still slightly larger, although the differences become minimal ${ }^{(51)}$.

The strength of the present study was the large populationbased cohort, which included many non-Dutch participants who were followed from early pregnancy onwards. We selected healthy infants with a normal and appropriate pregnancy outcome to comprise a healthy study population, due to exclusion of pre-term born and small-for-gestational age children. Furthermore, we analysed growth in weight, length and weight-for-length and were able to include many known risk factors for early growth ${ }^{(37)}$. The present study is one of the first to investigate ethnic differences in growth in weight and length in infancy. Most studies in this area measure weight alone and are unable to differentiate between various ethnic groups. Nevertheless, we realise that some limitations should be considered. First, a part of our feeding data relied on parental recall. Most of the information that we used was collected prospectively, and our data were completed with retrospective information at the age of 5 years. Yet, an intraclass correlation coefficient $>0.75$ is quite sufficient. Second, length during infancy is prone to measurement error. However, this error is not related to ethnicity or infant feeding, and therefore this will not bias the results. Our large numbers justify this error. Furthermore, our feeding data did not capture information about the quantity of the food and the type of formula and complementary food that was given to the children. Therefore, it was not possible to examine the energy intake of each child. It may transpire that mothers from Turkish and Moroccan origin give breast-feeding and supplement with formula feeding, which can lead to extra food intake and extra gain in weight and length ${ }^{(28)}$. However, we did not find faster growth of mixed-fed infants in our analyses compared with those infants who were formula-fed alone, thus could not confirm this hypothesis. Lastly, reverse causality could have created bias: infants with weight gain below their average curve trajectories may be deliberately supplemented with formula feeding or solid foods in an effort to reverse those trends.

In conclusion, we found high growth rates in weight and length during the first 6 months of life in infants from Turkish, Moroccan and African origin compared with Dutch infants. Although there were ethnic differences in feeding patterns, only in African infants could these patterns partly explain the higher growth rates in this group. The low prevalence of initiation of breast-feeding and the early introduction of complementary food in these mothers need further attention. More research is needed to elucidate the underlying mechanisms of the high infant growth rate in Turkish and Moroccan infants.

\section{Acknowledgements}

M. L. A. d. H. and T. G. M. V. developed the concept of the present study as part of the ABCD study. M. L. A. d. H. conducted the analyses. All co-authors provided statistical advice. M. v. E., R. J. B. J. G. and T. G. M. V. are the project managers of the ABCD study, and they coordinated the data collection. M. L. A. d. H. was involved in obtaining part of the data. All the authors contributed to interpreting the results and writing the manuscript, and they have read and approved the final version. None of the authors has a personal or financial conflict of interest. The ABCD study was financially supported by the Academic Medical Centre, Amsterdam, the Public Health Services, Amsterdam and the Netherlands Organization for Health Research and Development, The Hague. The present study would not have been possible without the participants, the midwife practices, the hospitals and the youth health care centres in Amsterdam, the Netherlands.

\section{References}

1. Ogden CL, Carroll MD, Curtin LR, et al. (2010) Prevalence of high body mass index in US children and adolescents, 2007-2008. JAMA 303, 242-249. 
2. Allcock DM, Gardner MJ \& Sowers JR (2009) Relation between childhood obesity and adult cardiovascular risk. Int J Pediatr Endocrinol 2009, 108187.

3. Corvalan C, Uauy R, Stein AD, et al. (2009) Effect of growth on cardiometabolic status at 4 y of age. Am J Clin Nutr 90 $547-555$

4. Freedman DS, Dietz WH, Srinivasan SR, et al. (1999) The relation of overweight to cardiovascular risk factors among children and adolescents: the Bogalusa Heart Study. Pediatrics 103, 1175-1182.

5. Freedman DS, Khan LK, Dietz WH, et al. (2001) Relationship of childhood obesity to coronary heart disease risk factors in adulthood: the Bogalusa Heart Study. Pediatrics 108, $712-718$

6. I'Allemand D, Wiegand S, Reinehr T, et al. (2008) Cardiovascular risk in 26,008 European overweight children as established by a multicenter database. Obesity (Silver Spring) 16, 1672-1679.

7. Fredriks AM, Buren van S, Sing RA, et al. (2005) Alarming prevalences of overweight and obesity for children of Turkish, Moroccan and Dutch origin in The Netherlands according to international standards. Acta Paediatr $\mathbf{9 4}$ 496-498

8. Kolsgaard ML, Andersen LF, Tonstad S, et al. (2008) Ethnic differences in metabolic syndrome among overweight and obese children and adolescents: the Oslo Adiposity Intervention Study. Acta Paediatr 97, 1557-1563.

9. Saxena S, Ambler G, Cole TJ, et al. (2004) Ethnic group differences in overweight and obese children and young people in England: cross sectional survey. Arch Dis Child 89, 30-36.

10. Lynch WC, Heil DP, Wagner E, et al. (2007) Ethnic differences in BMI, weight concerns, and eating behaviors: comparison of Native American, White, and Hispanic adolescents. Body Image 4, 179-190.

11. Singh GK, Kogan MD, Van Dyck PC, et al. (2008) Racial/ ethnic, socioeconomic, and behavioral determinants of childhood and adolescent obesity in the United States: analyzing independent and joint associations. Ann Epidemiol 18, 682-695.

12. Whitaker RC \& Orzol SM (2006) Obesity among US urban preschool children: relationships to race, ethnicity, and socioeconomic status. Arch Pediatr Adolesc Med 160 $578-584$.

13. Schokker DF, Visscher TL, Nooyens AC, et al. (2007) Prevalence of overweight and obesity in the Netherlands Obes Rev 8, 101-108.

14. Barker DJ, Winter PD, Osmond C, et al. (1989) Weight in infancy and death from ischaemic heart disease. Lancet ii $577-580$

15. Barker DJ (2003) The developmental origins of adult disease Eur J Epidemiol 18, 733-736.

16. Gluckman PD, Hanson MA, Cooper C, et al. (2008) Effect of in utero and early-life conditions on adult health and disease. $N$ Engl J Med 359, 61-73.

17. Hof MHP, van Dijk AE, van Eijsden, et al. (2011) Comparison of growth between native and immigrant infants between 0-3 years from the Dutch ABCD cohort. Ann Hum Biol (In the Press).

18. Dennison BA, Edmunds LS, Stratton HH, et al. (2006) Rapid infant weight gain predicts childhood overweight. Obesity (Silver Spring) 14, 491-499.

19. Gillman MW, Rifas-Shiman SL, Camargo CA Jr, et al. (2001) Risk of overweight among adolescents who were breastfed as infants. JAMA 285, 2461-2467.
20. Gillman MW, Rifas-Shiman SL, Berkey CS, et al. (2006) Breast-feeding and overweight in adolescence: withinfamily analysis [corrected]. Epidemiology 17, 112-114.

21. Gunnarsdottir I, Schack-Nielsen L, Michaelsen KF, et al. (2010) Infant weight gain, duration of exclusive breast-feeding and childhood BMI - two similar follow-up cohorts. Public Health Nutr 13, 201-207.

22. Kramer MS, Guo T, Platt RW, et al. (2004) Feeding effects on growth during infancy. J Pediatr 145, 600-605.

23. Griffiths LJ, Smeeth L, Hawkins SS, et al. (2009) Effects of infant feeding practice on weight gain from birth to 3 years. Arch Dis Child 94, 577-582.

24. Kramer MS (1981) Do breast-feeding and delayed introduction of solid foods protect against subsequent obesity? J Pediatr 98, 883-887.

25. Kramer MS (2010) Breastfeeding, complementary (solid) foods, and long-term risk of obesity. Am J Clin Nutr 91, 500-501.

26. Schack-Nielsen L, Sorensen TI, Mortensen EL, et al. (2010) Late introduction of complementary feeding, rather than duration of breastfeeding, may protect against adult overweight. Am J Clin Nutr 91, 619-627.

27. Wilson AC, Forsyth JS, Greene SA, et al. (1998) Relation of infant diet to childhood health: seven year follow up of cohort of children in Dundee infant feeding study. BMJ 316, 21-25.

28. Bulk-Bunschoten AM, Pasker-de Jong PC, van Wouwe JP, et al. (2008) Ethnic variation in infant-feeding practices in the Netherlands and weight gain at 4 months. J Hum Lact 24, 42-49.

29. Rossem van L, Vogel I, Steegers E, et al. (2009) Breastfeeding patterns among ethic minorities: the generation $\mathrm{R}$ study. J Epidemiol Community Health 64, 1080-1085.

30. Bentley ME, Dee DL \& Jensen JL (2003) Breastfeeding among low income, African-American women: power, beliefs and decision making. J Nutr 133, 305S-309S.

31. Bronner YL, Gross SM, Caulfield L, et al. (1999) Early introduction of solid foods among urban African-American participants in WIC. J Am Diet Assoc 99, 457-461.

32. Forste R, Weiss J \& Lippincott E (2001) The decision to breastfeed in the United States: does race matter? Pediatrics 108, 291-296.

33. Benn RT (1971) Some mathematical properties of weightfor-height indices used as measures of adiposity. Br J Prev Soc Med 25, 42-50.

34. Ong KK, Emmett PM, Noble S, et al. (2006) Dietary energy intake at the age of 4 months predicts postnatal weight gain and childhood body mass index. Pediatrics 117, e503-e508.

35. van Eijsden M, Vrijkotte TG, Gemke RJ, et al. (2010) Cohort profile: The Amsterdam Born Children and their Development (ABCD) Study. Int J Epidemiol (Epublication ahead of print version 2 September 2010).

36. Stronks K, Kulu-Glasgow I \& Agyemang C (2009) The utility of 'country of birth' for the classification of ethnic groups in health research: the Dutch experience. Ethn Health 14, $1-14$.

37. Rebhan B, Kohlhuber M, Schwegler U, et al. (2009) Infant feeding practices and associated factors through the first 9 months of life in Bavaria, Germany. J Pediatr Gastroenterol Nutr 49, 467-473

38. Gardner DS, Hosking J, Metcalf BS, et al. (2009) Contribution of early weight gain to childhood overweight and metabolic health: a longitudinal study (EarlyBird 36). Pediatrics 123, e67-e73. 
39. Monteiro PO \& Victora CG (2005) Rapid growth in infancy and childhood and obesity in later life - a systematic review. Obes Rev 6, 143-154.

40. Ay L, Van Houten VA, Steegers EA, et al. (2009) Fetal and postnatal growth and body composition at 6 months of age. J Clin Endocrinol Metab 94, 2023-2030.

41. Botton J, Heude B, Maccario J, et al. (2008) Postnatal weight and height growth velocities at different ages between birth and $5 \mathrm{y}$ and body composition in adolescent boys and girls. Am J Clin Nutr 87, 1760-1768.

42. Chivers P, Hands B, Parker H, et al. (2010) Body mass index, adiposity rebound and early feeding in a longitudinal cohort (Raine Study). Int J Obes (Lond) 34, 1169-1176.

43. Coleman BL, Gutmanis I, Larsen LL, et al. (2009) Introduction of solid foods: do mothers follow recommendations? Can J Diet Pract Res 70, 135-140.

44. Eijsden van M, Berkenpas ME \& Wal van der MF (2009) Breastfeeding in a multiethnic population: the role of the (prospective) father and grandmother. Tijdschrift voor gezondheidswetenschappen (J Health Sci) 87, 100-108.

45. Satcher DS (2001) DHHS blueprint for action on breastfeeding. Public Health Rep 116, 72-73.
46. Larsen T, Greisen G \& Petersen S (1997) Intrauterine growth correlation to postnatal growth influence of risk factors and complications in pregnancy. Early Hum Dev 47, 157-165.

47. Leunissen RW (2009) Timing and tempo of first-year rapid growth in relation to cardiovascular and metabolic risk profile in early adulthood. JAMA 301, 2234-2242.

48. Elks CE, Loos RJ, Sharp SJ, et al. (2010) Genetic markers of adult obesity risk are associated with greater early infancy weight gain and growth. PLoS Med 7, e1000284.

49. Graitcer PL \& Gentry EM (1981) Measuring children: one reference for all. Lancet ii, 297-299.

50. Habicht JP, Martorell R, Yarbrough C, et al. (1974) Height and weight standards for preschool children. How relevant are ethnic differences in growth potential? Lancet i, 611-614.

51. Talma H, Schonbeck Y, Bakker B, et al. (2010) Groeidiagrammen 2010: Handleiding bij het meten en wegen van kinderen en het invullen van groeidiagrammen (Growth Charts 2010: Guide to Measuring and Weighing Children and the Filling of Growth Charts). Leiden, The Netherlands: TNO kwaliteit van leven. 